\title{
Immunohistochemical Study of Choledochal Cyst Wall
}

\author{
Linda Ozolina*, Mara Pilmane*, Arnis Engelis** \\ * Institute of Anatomy and Anthropology, Riga Stradins University, Riga, Latvia \\ **University Children's Hospital, Riga, Latvia
}

\begin{abstract}
Summary
Introduction. Choledochal cysts are rare congenital anomalies that appear as localized cystic or fusiform biliary tree dilatations. Choledochal cyst is a rare congenital anomaly with a reported incidence of 1 in 100,000-150,000 live births (7). Nearly $25 \%$ of choledochal cysts are diagnosed in the first year of life and $60 \%$ in the first decade, but $20 \%$ detected are after the age of 20 years (12).

Aim of the Study. The pathogenesis of choledochal cysts remains still unknown. The aim of this study was to examine relative distribution of growth factors, neuropeptide-containing innervation and apoptosis in the choledochal cyst wall.

Materials and methods. Histopathological study of choledochal cyst wall was conducted on four patients aging from six months till 14 years. Tissues were processed for haematoxylin - eosin staining, immunohistochemistry for PGP 9.5, NGFR, NF, VEGF, CGRP and TUNEL method.

Results. In overview sections we observed granulation tissue, blood vessel sanguineness and inflammatory infiltrate. Fibromuscular coat was thickened showing thick collagen bundles and dispersed smooth myocytes. Serosa was present in one case, all the rest demonstrated adhesions with dilated blood vessels and perivascular infiltrate. PGP 9.5 - containing nerve fibers and nerve fiber bundles were mostly observed in moderate and large amounts. NGFR in large amount was seen in nerve fiber bundles and nerve fibers among smooth muscle cells in the wall of small blood vessels. NF positive structures - nerve fibers and nerve fiber bundles were found in moderate amount, except one case were the expression was very low. CGRP was found in neuroendocrine cells, nerve fiber bundles, leukocytes, inflammatory cells and endoteliocytes. Expression varied from low to moderately high. VEGF expression in most patient material was negative. Apoptosis was observed in inflammatory cells and epiteliocytes, showing large amount of
\end{abstract} positive structures.

Conclusions. The amount of PGP 9.5 and CGRP demonstrates relatively good cyst wall innervation. Marked expression of NGFR proves still existing neuronal growth stimulation despite relatively unchanged neuronal cytoskeleton. Negative expression of VEGF proves lack of ischemia. Apoptosis mainly affects inflammatory cells and epiteliocytes, while the choledochal cyst wall presumably is composed of functionaly viable tissue.

Key words: choledochal cyst, pathogenesis, growth factors, innervation, apoptosis.

\section{INTRODUCTION}

Choledochal cysts are rare congenital anomalies that appear as localized cystic or fusiform biliary tree dilatations. Choledochal cyst is a rare congenital anomaly with a reported incidence of 1 in 100,000150,000 live births (7). Nearly $25 \%$ of choledochal cysts are diagnosed in the first year of life and $60 \%$ in the first decade, but $20 \%$ detected are after the age of 20 years (12).

Recent studies are aimed on early prenatal diagnosis, which results in earlier definitive surgery and less complications at an older age (4), new techniques of surgical treatment (16) .

Earlier studies indicate the reduction in the number of ganglion cells in the narrow portion of the choledochal cysts (10). There is also evidence of the increasing rate of epithelial metaplasia in the walls of choledochal cysts with advancing age (9). Latest studies try to explain the role of matrix metalloproteinase 1 and 2 in choledochal cyst formation (13). Many recent studies are conducted on liver tissue due to the frequent association of choledochal cysts and liver fibrosis. In one of these studies as pathogenic factors were analysed cytokeratins and human leukocyte antigens-DR (5).

\section{AIM OF THE STUDY}

Histopathological examination of the choledochal cyst was performed in order to determine the factors which might be related to its development and further prognosis. The aim of this study was to examine relative distribution of growth factors, neuropeptide-containing innervation and apoptosis in the choledochal cyst wall.

\section{MATERIALS AND METHODS}

Histopathological study of choledochal cyst wall was conducted on four patients aging from six months till 14 years. Material from operations that was studied was from two girls and two boys. Methods:

Routine histological method. Each biopsy material was fixed in $10 \%$ formalin for 24 hours. Afterwards the fragment of tissue was dehydrated and embedded in paraffin. 5-8 $\mu \mathrm{m}$ thick sections were made from the blocks and stained with hematoxylin and eosin. 
Immunohistochemical method. Fragments of tissue were fixed for 24 hours in a mixture consisting of $2 \%$ formaldehyde and $0.2 \%$ picric acid in a $0.1 \mathrm{M}$ phosphate buffer $(p H$ 7.2). Then tissue fragments were washed for 12 hours in a thyroid buffer containing $10 \%$ of sucrose. Subsequently all biopsy specimens were embedded in paraffin wax. Tissue were processed for: nerve growth factor receptor (NGFR, code M3507, working dilution 1:150, Dako, Denmark), protein gene product 9.5 (PGP 9.5, code Z5116, working dilution 1:600, Dako, UK), calcitonin gene related peptide (CGRP, code B47-100, working dilution 1:10, Euro Diagnostica, Sweden), neurofilaments (NF, code M0762, working dilution 1:100, Dako, Denmark), vascular endothelial growth factor (VEGF, code M7273, working dilution 1:50, Dako, Denmark) by use of biotin - streptavidin immunohistochemical method (8).

TUNEL method. Apoptosis was determined using TUNEL method (15).

For marking of relative frequency in the tissue of the immunohistochemically determined positive structures we used the method frequently described in literature - the semi-quantitative counting method (17). Following codes were used: 0 - no positive structures seen, $0 /+$ occasional positive structures seen, +- few positive structures seen, ++ - moderate amount of positive structures seen, +++- numerous positive structures seen.

\section{RESULTS}

Mucosal epithelial tissues were fragmentary preserved in two patient material. Scattered glandular tissues were also found in two specimens. In all sections we observed granulation tissue, blood vessel sanguineness and inflammatory infiltrate (Fig. 1). Inflammatory cells infiltrated epithelium, lamina propria, muscle layer and especially connective tissue close to lymph and blood vessels. Fibromuscular coat was thickened showing thick collagen bundles and dispersed smooth myocytes (Fig. 2). Serosa was present in only one case, all the rest demonstrated adhesions with dilated blood vessels and perivascular infiltrate.

NGFR positive nerve fibers were seen in mucosal layer, blood vessel wall and also as variable size nerve fiber bundles in different parts of choledochal cyst wall (Fig. 3). Mostly we found numerous, less often moderate amounts of NGFR positive structures (Table 1).

PGP 9.5 - containing nerve fibers and nerve fiber bundles were observed in mucosa, blood vessel wall and also in fibromuscular and outer coat (Fig. 4). All tissue showed moderate to high expression of PGP 9.5.

The most variable expression - from few positive structures in three specimens to moderate and numerous amount of positive structures in two patient material - was that of CGRP. CGRP was expressed in occasional neuroendocrine cells, nerve fiber bundles and macrophages (Fig. 5).

Neurofilaments - containing nerve fibers were mainly found in moderate amounts except one patient material, where only occasional immunoreactive for peptide structures were observed (Fig. 6).

VEGF expression in choledochal cyst wall was almost in all cases negative with the exception of two specimens, where occasional positive structures were found. VEGF marked endotheliocytes and macrophages (Fig. 7).

Apoptotic cells were seen in three patient materials, while one patient material was completely negative. Apoptosis was richly observed in inflammatory cells and epiteliocytes, showing numerous positive structures (Fig. 8). To a lesser extent apoptotic process affected fibrous tissue cells and glandular tissue - few to moderate amount of positive structures was found.

Table 1. Relative appearance of growth peptides, neuropeptide-containing innervations and cytoskeleton markers in the patient material

\begin{tabular}{|l|l|l|l|l|l|}
\hline & NGFR & PGP 9.5 & CGRP & NF & VEGF \\
\hline Patient 1 & $++/+++$ & ++ & $+/++$ & ++ & + \\
\hline & $++/+++$ & ++ & + & ++ & - \\
\hline Patient 2 & $++/+++$ & $++/+++$ & + & $+/++$ & - \\
\hline Patient 3 & +++ & $++/+++$ & $++/+++$ & $0 /+$ & - \\
\hline & +++ & $++/+++$ & $+/++$ & - & - \\
\hline Patient 4 & +++ & $++/+++$ & $++/+++$ & $++/+++$ & $0 /+$ \\
\hline $\begin{array}{l}\text { Mean } \\
\text { value }\end{array}$ & +++ & $++/+++$ & $+/++$ & ++ & - \\
\hline
\end{tabular}

( 0 - no positive structures seen, $0 /+$ occasional positive structures seen, +- few positive structures seen, ++- moderate amount of positive structures seen, +++- numerous positive structures seen.)

\section{DISCUSSION}

Our results showed various changes in choledochal cyst wall structure. Epithelium was fragmentary preserved, fibromuscular coat consisted of dense collagen bundles and occasional smooth muscle bundles, serosa was present in two cases, all the rest showed thick adventitia. In literature there are data of sequential cyst wall histological appearance changes through three stages depending on age (18). Our data partially matched the younger the patient is the more poorly the muscle layer was developed. As the age increased there was more fibrous tissue. However, granulations were better developed in older patients, same for the extent of inflammatory cell infiltration.

As for innervation, our aim was to analyze neuronal growth stimulation, neuronal structure quantity and quality. Neuronal growth stimulation was studied in correlation with NGFR. As already mentioned, in most cases we found numerous, less often moderate amount of NGFR positive structures, which indicates quite strong neuronal growth stimulation. In addition to NGFR neuronal growth stimulatory function it also promotes fibroblast proliferation and inhibits myocyte development (2) which might explain poorly developed myocytes and dense fibrous tissue. As neuronal structure markers we used PGP 9.5 and CGRP. PGP 9.5 showed 
moderate number of positive structures, while the expression of CGRP greatly varied from slightly positive to large. CGRP expression was stronger in young patient group which corresponds with the data of Carrier (3). Neurofilaments characterize neuronal structure quality (11), which in our case was relatively good (moderate expression). From this we can see, that there is still existing neuronal growth stimulation despite relatively good quantity and quality of neuronal structures.

VEGF in reply to hypoxia promotes endotheliocyte proliferation (14). VEGF expression in our material was mainly negative, proving lack of ischemia.

Apoptotic cells were mostly observed in internal cyst wall layer affecting epitheliocytes and inflammatory cells. The high incidence of the apoptotic cells may be attributed to the reflux of pancreatic juice into the biliary system through an abnormally high junction between the common bile duct and the pancreatic duct, which is often mentioned as one of the ethiological factors (11). There is also data that bile from congenital choledochal cyst patients can promote the proliferation of epitheliocytes and human cholangiocarcinoma cells (19). To a lesser extent apoptotic process affected fibrous and glandular tissue cells. These results are probably indicative of functionally viable tissue forming cyst wall.

\section{CONCLUSIONS}

1. The cyst wall demonstrates rich PGP 9.5- and CGRP-containing nerve fibers innervation. Marked expression of NGFR proves still existing neuronal growth stimulation despite relatively unchanged neuronal cytoskeleton.

2. Mainly negative expression of VEGF proves lack of ischemia.

3. Apoptosis mainly affects inflammatory cells and epiteliocytes, that seems to be structures involved in the affected morphopathogenesis of cysts in other way seemingly functionaly viable tissue.

\section{Conflict of interest: None}

\section{REFERENCES}

1. Babbitt DP. Congenital choledochal cysts: new etiological concept based on anomalous relationships of the common bile duct and pancreatic bulb // Ann Radiol, (Paris) 1969;12:231-240

2. Botchkareva NV, Botchkarev VA, Chen LH, Lindner G, Paus R. A role for p75 neurotrophin receptor in the control of hair follicle morphogenesis // Dev boil, 1999 Dec 1;216(1):135-153

3. Carrier N, Connat JL. Rat common bile duct: structure, pharmacological responsiveness, CGRP innervation, and binding sites // Gen Comp Endocrinol, 1995 Nov;100(2):197-210

4. Foo DC, Wong KK, Lan LC, Tam PK. Impact of prenatal diagnosis on choledochal cysts and the benefits of early excision // J Paediatr Child Health, 2009 Jan-Feb;45(1-2):28-30

5. Gong ZH, Xiao X, Chen L. Hepatic fibrosis with choledochal cyst in infants and children - an immunohistochemical assessment // Eur J Pediatr Surg, 2007 Feb; 17(1):12-16

6. Hewitt PM, Krige JE, Bornman PC, Terblanche J. Choledochal cysts in adults // Br J Surg, 1995;82:382-385

7. Howard ER. Choledochal cysts // In: Howard ER. Surgery of liver disease in children. Oxford: Butterworth-Heineman; 1991:78-90

8. Hsu SM, Raine L. Protein A, avidin, and biotin in immunohistochemistry // J Histochem Cytochem, 1981 Nov;29(11):1349-1353

9. Komi N, Tamura T, Tsuge S, Miyoshi Y, Udaka H, Takehara H. Relation of patient age to premalignant alterations in choledochal cyst epithelium: histochemical and immunohistochemical studies // J Pediatr Surg, 1986 May;21(5):430-433

10. Kusunoki M, Saitoh N, Yamamura T, Fujita S, Takahashi T, Utsunomiya J. Choledochal cysts. Oligoganglionosis in the narrow portion of the choledochus // Arch Surg, 1988 Aug;123(8):984986

11. Lasek RJ, Phillips L, Katz MJ, Autilio-Gambetti L. Function and evolution of neurofilament proteīns // Ann N Y Acad Sci. 1985;455:462-478

12. Lipsett PA, Pitt HA, Colombani PM, Boitnott JK, Cameron JL. Choledochal cyst disease. A changing pattern of presentation // Ann Surg, 1994;220:644652

13. Mao YZ, Tang ST, Ruan QL. Expression of matrix metalloproteinase 1 and 2 in congenital choledochal cyst and its clinical significance // World J Pediatr, 2008 May;4(2):130-134

14. Millauer B., Shawver LK., Plate KH., Risau W., Ullrich A. Glioblastoma growth inhibited in vivo by a dominant-negative Flk-1 mutant // Nature, February 1994; 367(6463):576-579

15. Negoesku A, Guillermet C, Lorimier P, Brambilla E, Labat-Moleur F. Importance of DNA fragmentation in apoptosis with regard to TUNEL specificity // Biomed pharmacother, 1998;52(6):252-258

16. Palanivelu $C$, Rangarajan $M$, Parthasarathi $R$, Amar V, Senthilnathan P. Laparoscopic management of choledochal cysts: technique and outcomes-a retrospective study of 35 patients from a tertiary center // J Am Coll Surg, 2008 Dec;207(6):839-846

17. Pilmane M, Rumba I, Sundler F, Luts A. Patterns of distribution and occurrence of neuroendocrine elements in lungs of humans with chronic lung diseases // Proc. of Latvian Academy of Sciences, Section B, 1998; 52:144-152

18. Suruga K. Clinical and pathological study on choledochocyst // Jpn J Surg, 1973 Dec; 3(4):199_ 202

19. Wu GS, Zou SQ, Luo XW, Wu JH, Liu ZR. Proliferative activity of bile from congenital choledochal cyst patients // World J Gastroenterol, 2003 Jan;9(1):184-187

\author{
Address: \\ Linda Ozolina \\ RSU AAI \\ 9 Kronvalda Bulvaris \\ Riga, Latvia, LV-1001 \\ E-mail: linda.ozolinja@inbox.lv
}




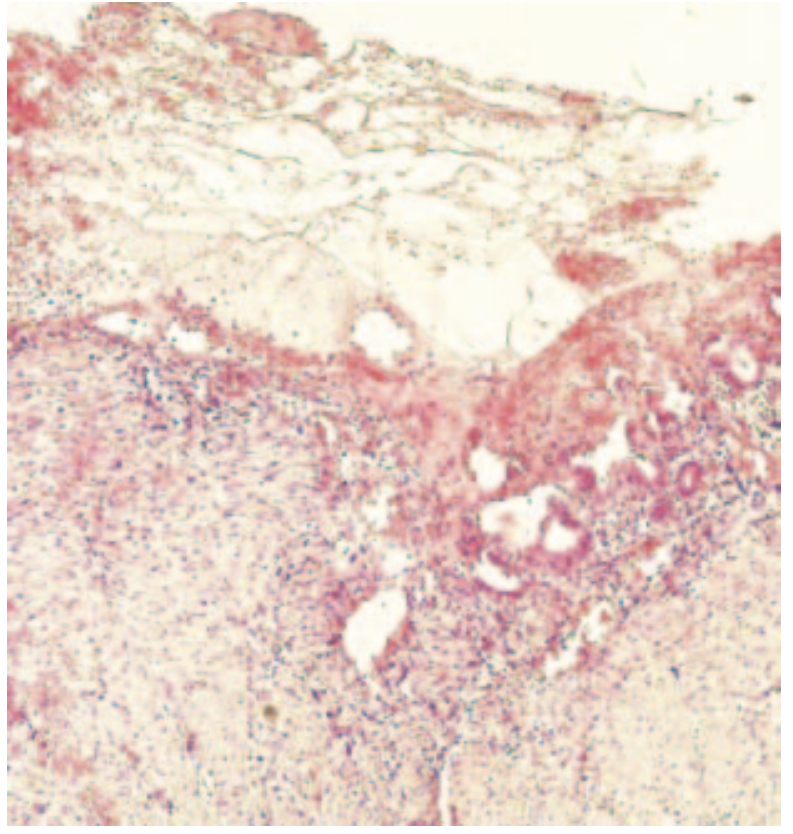

Fig. 1. Inner surface of the cyst covered with fibrin deposits. Inflammatory cell infiltrate and blood vessel sanguineness (H\&E x 100)

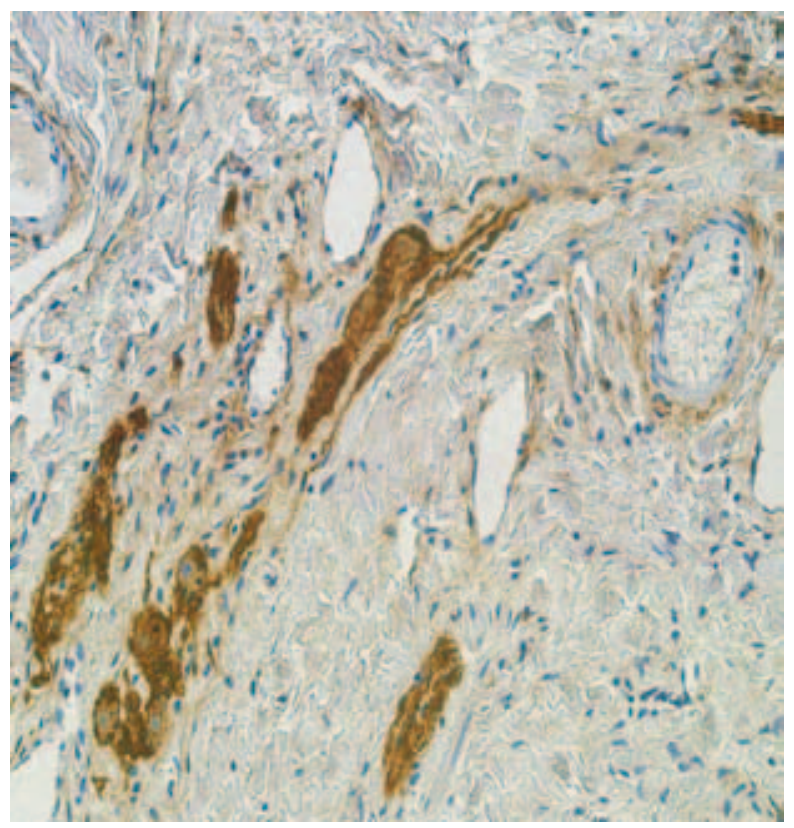

Fig. 3. Nerve fiber bundles mainly in fibromuscular coat and some fine nerve fibers which occupied space among smooth myocytes in blood vessel wall (NGFR IMH x 250)

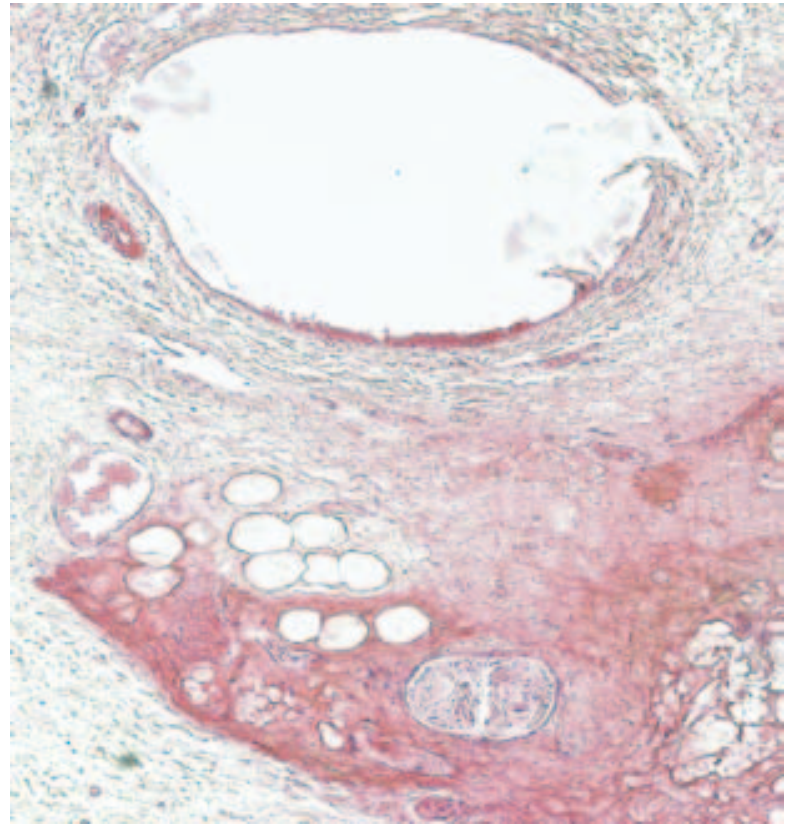

Fig. 2. Thickened fibrotic coat showed dilated lymph and blood vessels. Steatosis was often seen in the thick adhesions (HEE X 100)

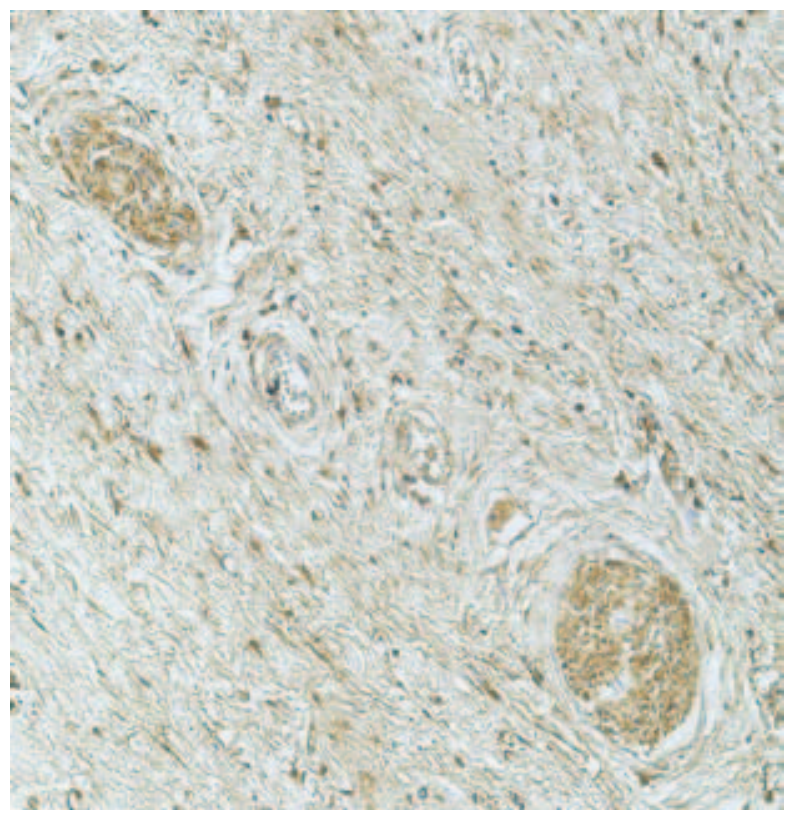

Fig. 4. PGP 9.5 positive nerve fibers and trunks found in fibromuscular coat (PGP 9.5 IMH $x$ 200) 


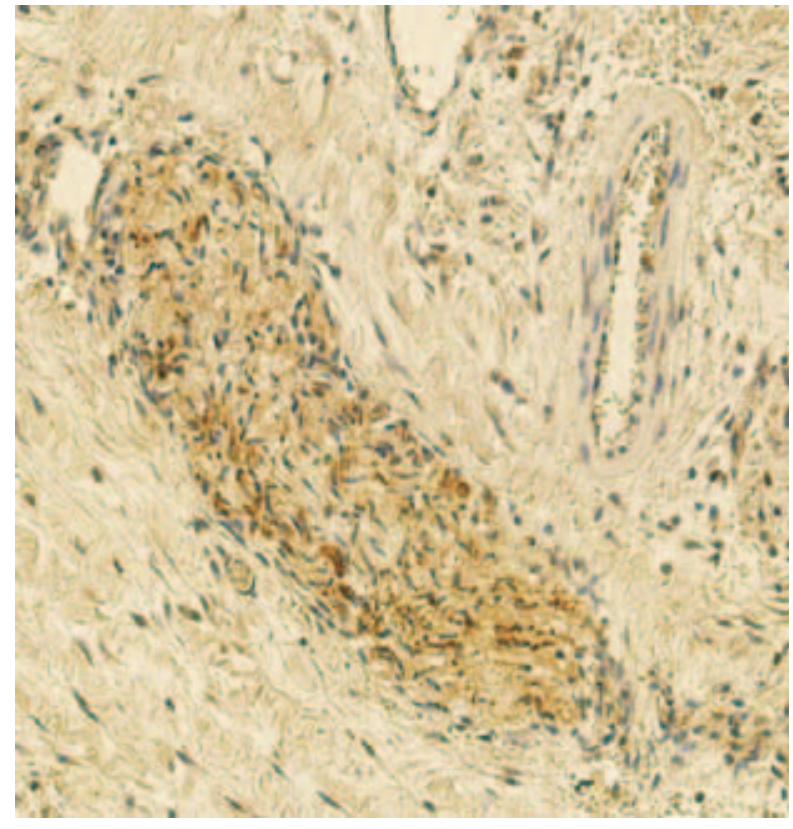

Fig. 5. Note nerve fiber bundles, some neuroendocrine cells and also fine nerve fibers positive for CGRP (CGRP IMH x 200)

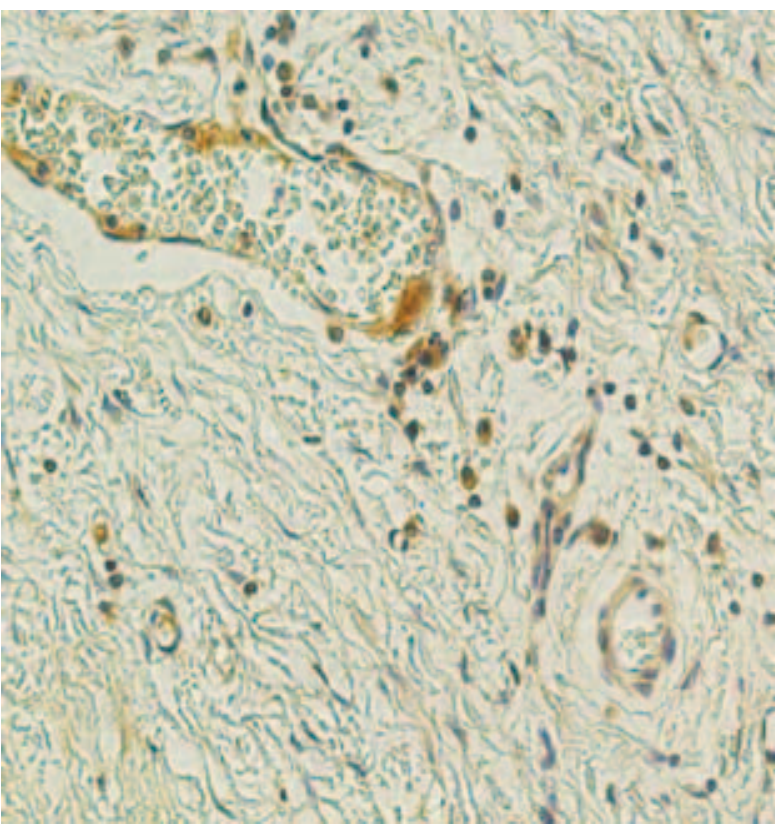

Fig. 7. VEGF expression in moderate number of endotheliocytes and macrophages (VEGF IMH $x$ 250)

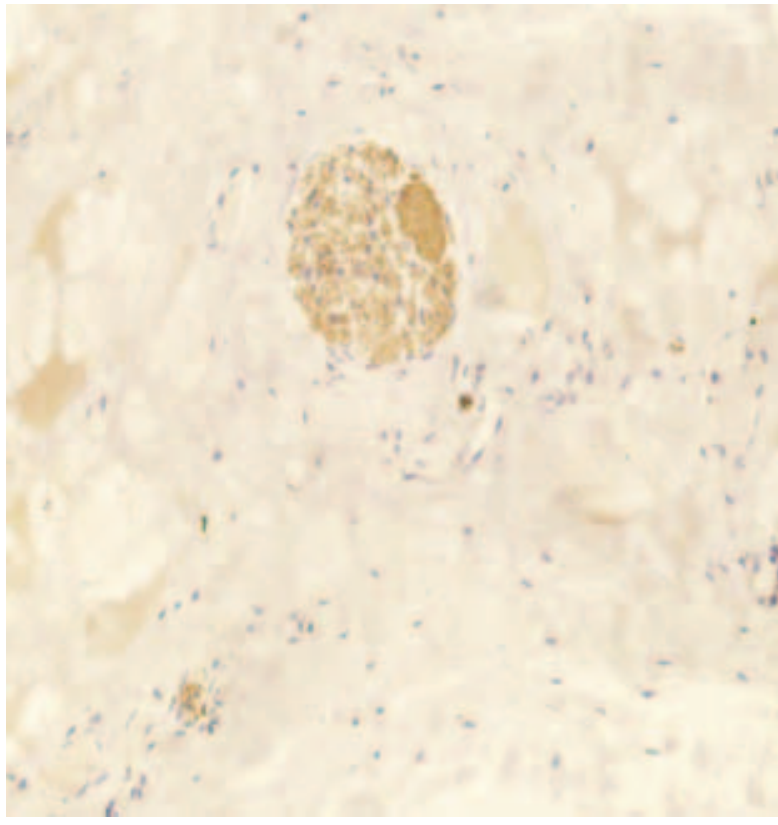

Fig. 6. Neurofilaments-containing nerve fibers in the adhesions (NF IMH $x$ 200)

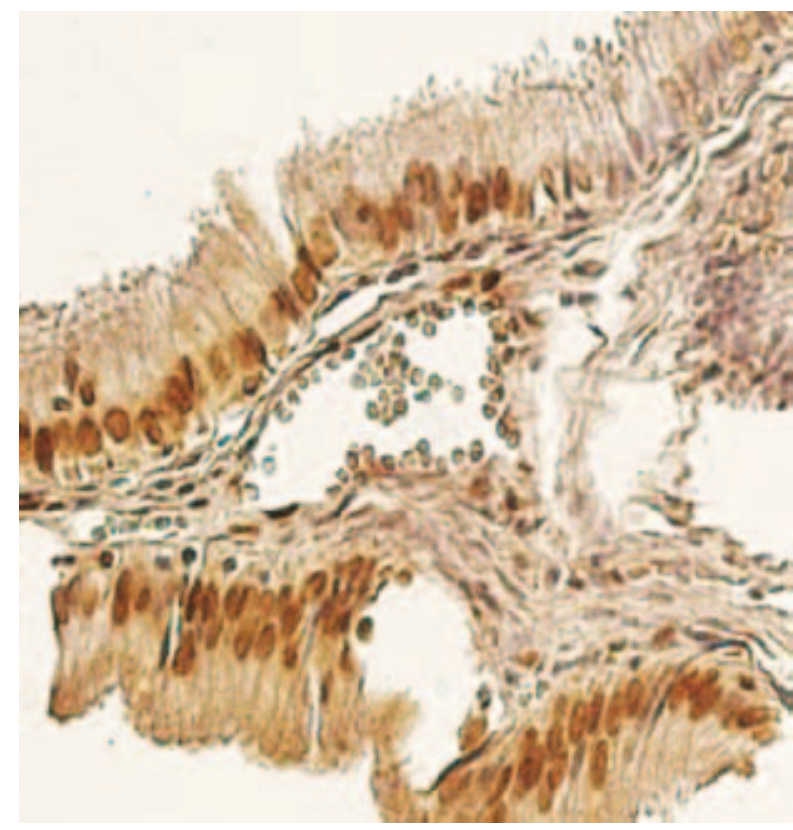

Fig. 8. Apoptosis affected almost all epithelium of cystic wall. (TUNEL X 250) 